\title{
Enhancing stability of Co gradient in nano-structured WC-Co functionally graded composites using graphene additives
}

\author{
Ali NASSER, ${ }^{* \dagger}$ Kazunari SHINAGAWA, ${ }^{* *}$ Hassan EL-HOFY* and Ahmed A. MONEIM ${ }^{*, * * *}$ \\ *Materials Science and Engineering Department, Egypt-Japan University of Science and Technology (E-JUST), \\ School of Innovative Design Engineering, New Borg El-Arab City, Postal Code 21934, Alexandria, Egypt \\ ** Department of Mechanical Engineering, Faculty of Engineering, Kyushu University, \\ 744 Motooka, Nishi-ku, Fukuoka 819-0395, Japan \\ *** Physical Chemistry Dept., National Research Center, El-Dokki-Giza, Egypt
}

\begin{abstract}
A new approach for stabilizing a predesigned Co gradient in the microstructure of nano WC-Co thinning structure via graphene additions is presented. For this purpose, laminated specimens of green WC-Co functionally graded material, having three layers structured, with and without graphene additions in the intermediate layer were sintered at solid and liquid sintering temperatures of 1290 and $1400^{\circ} \mathrm{C}$, respectively, using the hot isostatic pressing technique (HIP). With graphene additions, the mean average grain size of WC matrix phase is reduced, a new inter-phase layer is created and the amplitude of predesigned Co gradient, which had lost during liquid phase sintering of graphene-free WC-Co composite, is maintained through the cross section of the predesigned structure. As a consequence, the liquid state sintered specimens containing graphene show better hardness to toughness relationships compared to the graphene-free specimens fabricated under the same processing conditions. Such improvements are attributed to the extraordinary thermo-mechanical properties of graphene, and its beneficial role in grain refinement and creation of inter-phase layer that enables the stabilization of the predesigned Co-gradient.
\end{abstract}

@2016 The Ceramic Society of Japan. All rights reserved.

Key-words : Powder processing, Nano-powders, WC-Co, Functionally graded materials, Hot isostatic pressing, Fracture toughness, Hardness

[Received June 11, 2016; Accepted September 21, 2016]

\section{Introduction}

Tungsten carbide-cobalt (WC-Co) composites are well-known hard materials that have been implemented extensively in cutting and drilling tools industry. ${ }^{1-3)}$ Functionally graded material (FGM) WC-Co is a class of these composites combines two or more irreconcilable properties in the same component, for instance, hardness and fracture toughness. ${ }^{4)-6)}$ Generally, hardness and wear resistance are often improved at the expense of the fracture toughness, Meanwhile, the multi-layered structure is a possible solution used to improve them all in the same component. ${ }^{5)-7)}$ It is expected that, the low - cobalt layer will maintain high hardness and wear resistance, while the other layers, with relatively higher cobalt content, would have high fracture toughness. ${ }^{2)-4)}$ It was found that cobalt migration or homogenization due to liquid phase sintering (LPS) over $1300^{\circ} \mathrm{C}$ is the main obstacle to form dense particles of the multilayered WC-Co FGMs with a stable gradient structure. ${ }^{5), 6)}$ Up to now, all the reported approaches for WC-Co FGMs formation have some limitations either because of the high cost and complexity or the lack of the mechanical properties. ${ }^{7)}$ The initial attempt in this regard was a trail to create Co migration pressure driven by inward Ti diffusion and outward $\mathrm{N}$ diffusion during LPS of WC-Co composite containing TiN, to develop a rich - cobalt surface layer. ${ }^{8)}$ But this Co enriching layer was found to be narrow due to the limited

Corresponding author: A. Nasser; E-mail: ali.hassan@ejust.edu.eg * Publication of this international collaborative article is supported by JSPS Grants-in-Aid for Scientific Research (KAKENHI), Grant Number 252016 nitrogen diffusion. ${ }^{9)}$ Later, scholars discovered techniques based on post sintering and subsequent carburization at high temperature, which allowed building WC-Co FGM with distinguished microstructural layers. ${ }^{10)}$ This process as yet, the most applicable in the industry due to the simplicity and the cost consideration, despite the problem of brittle phase formation associated with it. ${ }^{2)}$ Recently, Fang. et al. claimed the ability to develop or maintain the Co gradient across WC-Co FGM through creating predesigned carbon (C) gradient. ${ }^{11)}$ They found that Co can be driven chemically to spread in the same direction of $\mathrm{C}$ diffusion. Further simulation work regarding $\mathrm{C}$ and Co gradient was done by Fan et al. in order to estimate the quantity of Co migration during LPS and to configure the effect of WC grain size. ${ }^{6), 12), 13)}$

In preference to free carbon, carbon nanostructured materials such as carbon nanotubes (CNTs) and graphene are newly emerging reinforcing agents for ceramic and polymeric composite materials because of their excellent mechanical and thermal properties beside their large binding surface area. ${ }^{15)-17)}$ However, a few reports have been engaged with utilizing these materials as reinforcing materials for WC-Co cermet. For instance, Zhang et al. recently reported the reinforcing effect of CNTs on the mechanical properties of nano WC-Co composite prepared by spark plasma sintering. ${ }^{14)}$ They found that the sintered nanocomposites containing CNTs combine the superior hardness to toughness relationships over that of the CNTs-free nanocrystalline WC-Co cermet fabricated under the same process conditions. Up to the authors' best knowledge, graphene $(G)$ has never been exploited as a reinforcing material for WC-Co cermet or stabilizer for the pre-designed Co gradient in WC-Co FGM, in spite of its utilization in a wide range of other applications. ${ }^{15), 18)-23)}$ This 
work has been undertaken to study the effect of graphene additions on stabilizing a predesigned Co gradient in green nano WCCo FGM of small thickness under solid and liquid states hot isostatic pressing (HIP) sintering conditions. Particular attention is given to the effect of graphene additives on hardness to toughness relationships of nano WC-Co FGM.

\section{Materials and methods}

\subsection{Powder preparation and characterization}

In the current study, the commercially available WC (purity 99.0\%, $950 \mathrm{~nm}$ average particle size, Kanto Chemical CompanyJapan) was used as a primary bulk phase while Co powder (purity 99.9\%, 1-2 $\mu \mathrm{m}$ average particle size) as received from Mitsuwa chemical-Japan was the metallic binder. G powder was imported from ACS material company having 2-10 nm sheet thickness, $5 \mu \mathrm{m}$ diameter and $20-40 \mathrm{~m}^{2} / \mathrm{g}$ specific surface area. Six WC-Co composites having a different $\mathrm{Co}$ and $\mathrm{G}$ compositions were prepared using dry mechanical alloying using PM 400 Planetary Ball Mill. The WC-5 wt.\% Co and WC- 15 wt.\% Co composites were prepared for the low and the high Co content layers, respectively. In addition, WC- 10 wt. \% Co composites with $0.0,0.1,0.2$ and $0.3 \mathrm{wt} . \% \mathrm{G}$, were prepared for the intermediate layer of three layer-transitional structures. These three layers form a predesigned step gradient of Co content. Mechanical milling parameters were optimized as $2.5-5 \mathrm{~h}$ milling time in zirconia media, $250 \mathrm{rpm}$ milling speed, and 10:1 balls to powder weight ratio. The alloying homogeneity and phase analysis were observed using LabX-XRD-6100 Shimadzu X-ray diffractometer. Also, JEM-HR-2100 transmission electron microscope (TEM) (JEOL USA Co. Ltd.) was used to analyze the morphology and particle size distribution of all powder mixtures after mechanical milling. Paraffin wax (1 wt.\%) dissolved in ethanol was added to the WCCo mixture just after mechanical milling and then it was dried using hot plate for $30 \mathrm{~min}$.

\subsection{Consolidation and characterization of multi- transitional structures}

The graded multi-transitional layer structure was formed by pressing the three different composites consecutively in a cylindrical steel mold. Thus, using $300 \mathrm{MPa}$ uniaxial hydraulic pressure, a thin three-transitional layered structure $(1.8-2 \mathrm{~mm})$ as shown in Fig. 1 was obtained.

According to Fig. 1 the specimens prepared for solid $1290^{\circ} \mathrm{C}$ $(1 \mathrm{H})$ and liquid $1400^{\circ} \mathrm{C}(2 \mathrm{H})$ states sintering temperatures are containing $0.0,0.1,0.2$ and $0.3 \mathrm{wt} . \% \mathrm{G}$ in the intermediate layer are assigned hereafter as $\mathrm{H} 0 \mathrm{G}, \mathrm{H} 1 \mathrm{G}$ and $\mathrm{H} 2 \mathrm{G}$ and $\mathrm{H} 3 \mathrm{G}$, respectively.

All specimens were subjected to degassing and dewaxing by slow heating in vacuum. Then these specimens were HIP sintered in argon at $186 \mathrm{MPa}$ and low $\left(1290^{\circ} \mathrm{C}\right)$ or high $\left(1400^{\circ} \mathrm{C}\right)$ sintering temperature using the fully automated AIP HIP 6-30 (American Isostatic Presses Inc.). Heating and pressing cycles at low and high sintering temperatures are illustrated schematically in Figs. 2(a) and 2(b) respectively.

The density of the consolidated samples was measured in water according to Archimedes principles. The specimen's crosssection was prepared for microstructural and elemental inspection according to Struers's stander, then it was polished to mirrorlike level in colloidal silica using Vibromet 2 Vibratory Polisher. Murakami reagent $\left(90 \% \mathrm{H}_{2} \mathrm{O}_{2}+10 \% \mathrm{HNO}_{3}\right)$ was used for etching under $70^{\circ} \mathrm{C}$ for $12 \mathrm{~min}$ to enable the evaluation of $\mathrm{WC}$ particle growth after sintering. Quanta FEG 250 scanning electron microscope (SEM) equipped with energy dispersive spectroscopy (EDS) was used to measure Co gradient over the transitional cross-section of the prepared WC-Co FGM specimens.

Macro-hardness (Hv) and fracture toughness $\left(K_{I C}\right)$ relationship was measured using hardness tester by applying $20 \mathrm{~kg}$ force for $15 \mathrm{~s}$. At least 5 readings were averaged for each data point. Indentation-induced palmqvist crack method based on Nihara's equation, Eq. (1) ${ }^{20)}$ was used for estimating fracture toughness.

$$
K_{I C}=0.203\left(\sum c / 4\right)^{\frac{-3}{2}}\left(\frac{2 D}{4}\right)^{2} H v
$$

Where $D$ is the indentation diagonal and $C$ is the crack length.

\section{Results and discussions}

\subsection{Powder characterization}

Figure 3 presents TEM images of WC-15\% Co (a), WC-5\%Co (b) $\mathrm{WC}-10 \% \mathrm{Co}-0.2 \% \mathrm{G}$ (c) composites. For graphene-free WCCo composites, the TEM images in Figs. 3(a) and 3(b) clearly reveal that the particles of WC powder after milling have a spherical shape, with an average size of 100-200 nm. Meanwhile, the Co metal binder exhibits small columnar shapes (pointed by red arrows) with an average size of about $50 \mathrm{~nm}$ after milling. The morphology and average size of WC and metallic Co nanoparticles were slightly reduced to the submicron size after milling in the presence of graphene sheets, as seen in Fig. 3(c), where the size of graphene sheets is not affected by the milling process.
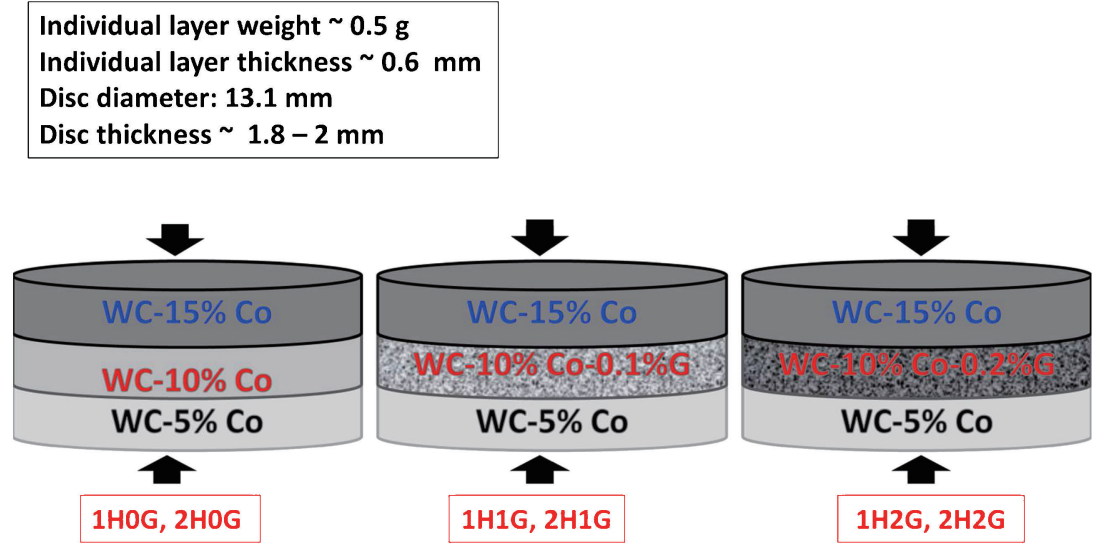

Fig. 1. Schematic illustrations of the three layered structure designs with and without graphene (G) addition in the intermediate layer at low $(1 \mathrm{H})$ and high $(2 \mathrm{H})$ sintering temperatures. 
Finally, the images in Fig. 3 clearly demonstrate that all the constituents of the milled composites homogeneously in contact with each other.

In brief, the present milling conditions of bulk WC and Co precursors resulted in the refinement and reduction of the overall particle size. Since graphene powder has enough ductility to resist the milling impact energy and avoid any reduction in its sheet size. It is worth mentioning that the reduction in WC particles of the micro size to the nano size range is of importance for two reasons; the first reason is related to the well-known potential of the nano particles to be consolidated at a lesser time and lower sintering temperature compared to the coarser particles
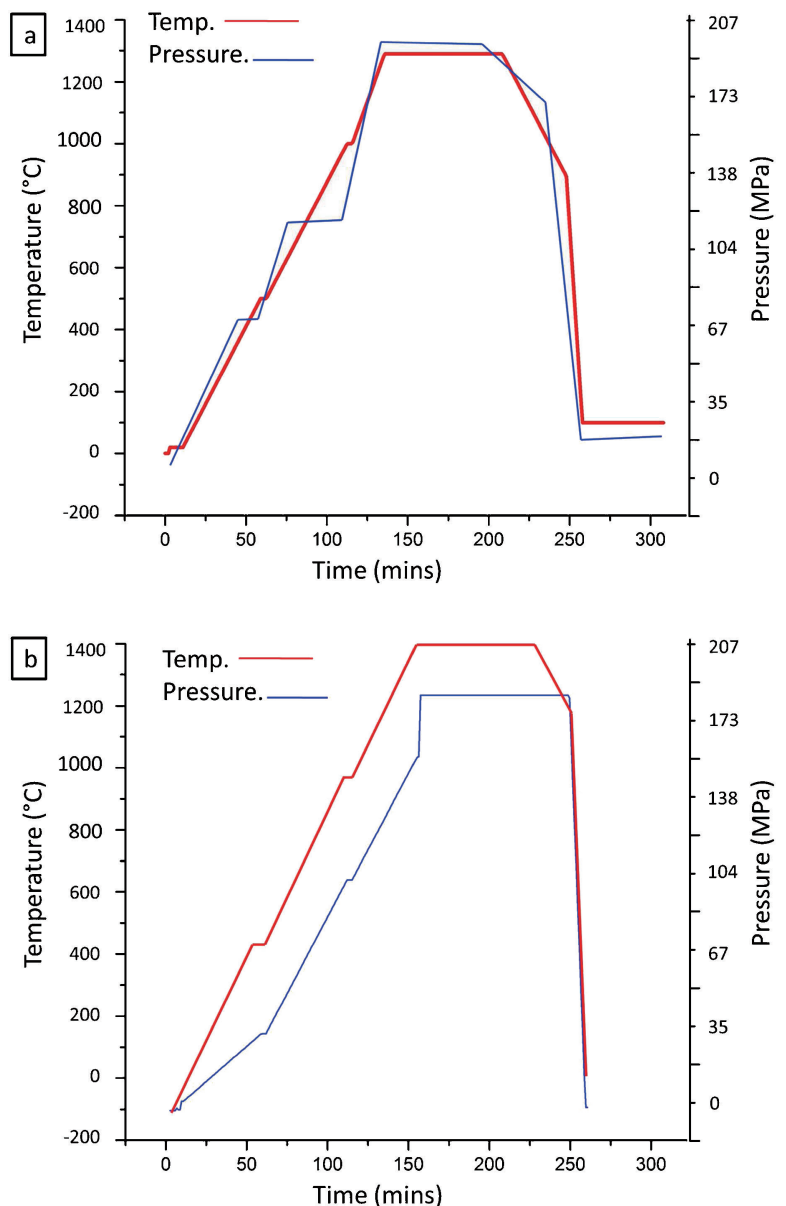

Fig. 2. Heating and pressing cycles at (a) low temperature $\left(1290^{\circ} \mathrm{C}\right)$ and (b) high temperature $\left(1400^{\circ} \mathrm{C}\right) \mathrm{HIPing}$ programs. due to their extra surface energy. ${ }^{21)-25)}$ The lower sintering temperature may restrict Co nanoparticles migration and the subsequent loses of the predesigned Co gradient during LPS process of WC-Co FGMs. ${ }^{21}$ ) The second reason is that the finer WC particle is usually needed to support the improvement of both hardness and fracture toughness of WC-Co composites. ${ }^{22)}$

Figure 4 presents XRD patterns of the milled WC-5\%Co, WC- $10 \mathrm{Co}-x \% \mathrm{G}(x=0.0,0.1,0.2$ and $0.3 \mathrm{wt} . \%)$, WC- $15 \%$ Co mixed powders. The XRD pattern of as received graphene, WC and Co powders are also given for comparison. In reference to the XRD database provided by National Institute for Materials Science in Japan (NIMS). All the milled powders, have combined reflection lines typical to hexagonal closed pack (HCP) structure of WC (space group P6m2 No. 187), faced center cubic (FCC) structure of metallic Co (space group P63mc No. 186). The graphitic structure of graphene (space group R-3m No. 166) is also recognized in the diffraction patterns of WC-10Co- $x \%$ $\mathrm{G}(x=0.1,0.2$ and $0.3 \mathrm{wt} . \%)$ milled powders. It is interesting to report that, neither surfactants nor other functionalization method was used to facilitate graphene mixing with $\mathrm{WC}-\mathrm{Co}$ matrix.

\subsection{Effect of graphene addition on densification, grain size and microstructure features}

In this section the effects of HIP sintering of solid and liquid states sintering temperatures on densification, grain size and microstructure features of three green WC-Co composite compacts with triple layers structured as well as pre-designed Co gradient are clarified.

Table 1 summarizes the density and relative density of H0G, $\mathrm{H} 1 \mathrm{G}, \mathrm{H} 2 \mathrm{G}$ and $\mathrm{H} 3 \mathrm{G}$ composites sintered at low and high temperatures. The rule of mixture was applied to calculate the composites theoretical densities. Apparently, the limited available load of the uniaxial hydraulic cold pressing machine which was used for the green compacts preparation seems to retard full pores elimination, so that $9-12 \%$ of the theoretical density was lost for all specimens after sintering. Particularly, the generated defects in microstructure due to the LPS caused $2 \mathrm{H}$ samples to suffer lowered relative density. However, porosity analysis shows higher densification results as will be discussed later. In Table 1 the specimens subjected to solid state sintering, $1 \mathrm{H}$, show a slight trend to increase their relative density with graphene addition. On the other hand, those subjected to liquid state sintering, $2 \mathrm{H}$, show an obvious increase of their relative density with graphene addition up to $0.2 \%$. Further increment in graphene content up to $0.3 \%$, however, reduces significantly the relative density of the nanocomposites. Such a significant reduction in the relative density of $\mathrm{H} 3 \mathrm{G}$ specimen leads to its delamination and hence its further characterization is impeded.
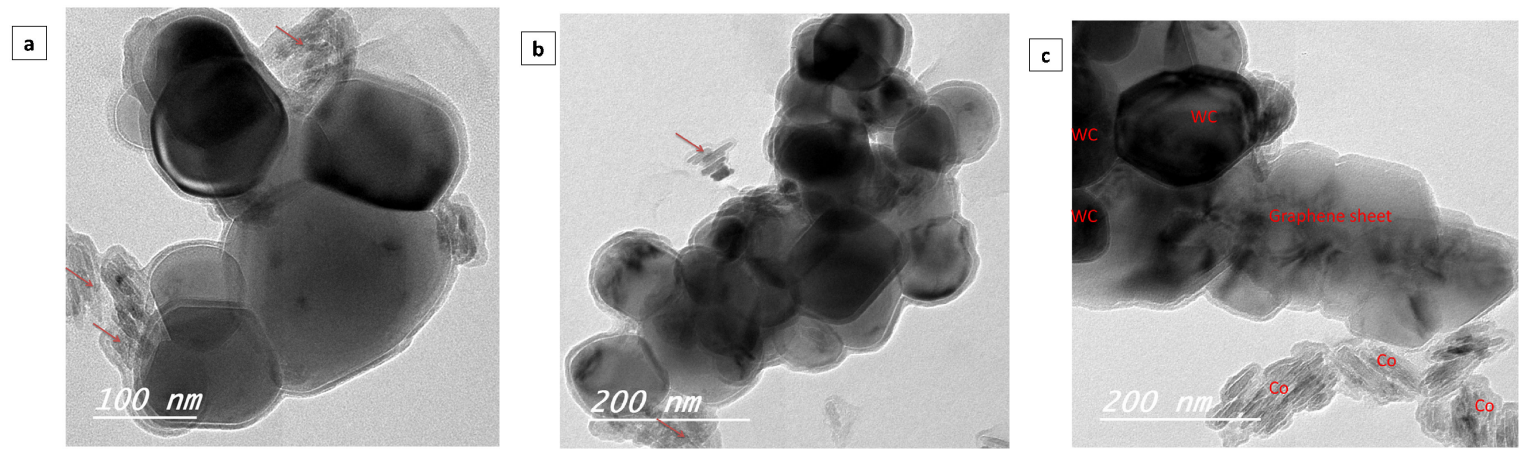

Fig. 3. TEM images of WC-15\% Co (a) WC-5\% Co (b), and WC-10\%Co- $0.2 \% \mathrm{G}$ (c) composites after milling for $2.5 \mathrm{~h}$ 


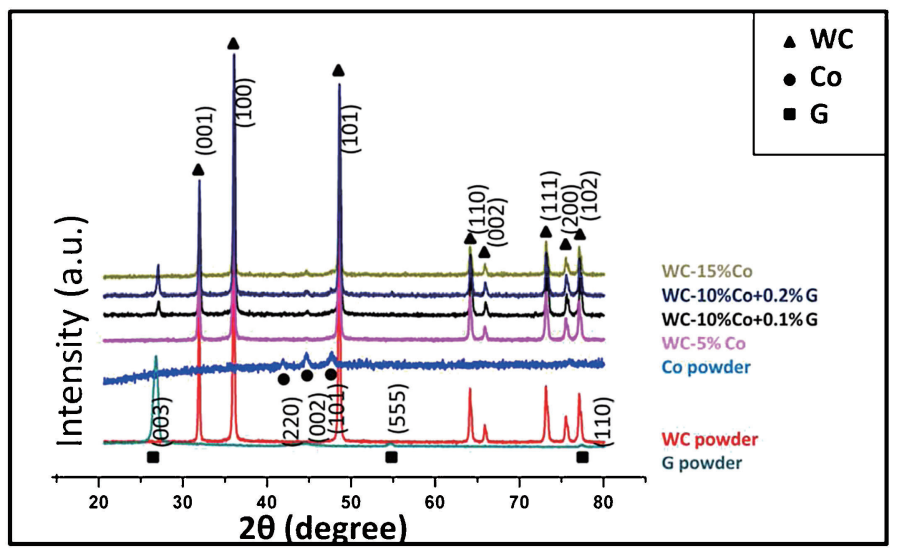

Fig. 4. Indexed XRD patterns of milled Co, WC and WC-5\%Co, WC-10Co- $x \% \mathrm{G}(x=0.0,0.1,0.2 \mathrm{wt} \%)$, WC-15\%Co mixed powders.

Table 1. Measured values for weights and densities of different sintered specimens

\begin{tabular}{ccc}
\hline Sample & Density $(\mathrm{g} / \mathrm{cc})$ & Relative density $(\% \mathrm{TD})$ \\
\hline $1 \mathrm{H} 0 \mathrm{G}$ & 13.45 & 90.2 \\
$1 \mathrm{H} 1 \mathrm{G}$ & 13.45 & 90.4 \\
$1 \mathrm{H} 2 \mathrm{G}$ & 13.45 & 90.8 \\
$1 \mathrm{H} 3 \mathrm{G}$ & 13.10 & 88.6 \\
$2 \mathrm{H} 0 \mathrm{G}$ & 12.45 & 83.4 \\
$2 \mathrm{H} 1 \mathrm{G}$ & 13.05 & 87.7 \\
$2 \mathrm{H} 2 \mathrm{G}$ & 13.15 & 88.6 \\
$2 \mathrm{H} 3 \mathrm{G}$ & 12.35 & 83.4 \\
\hline
\end{tabular}

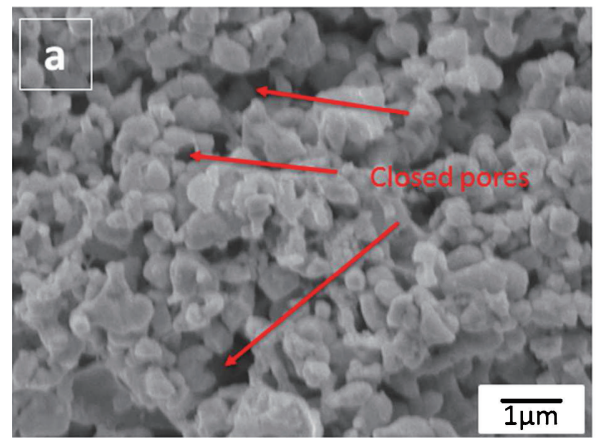

Table 2. Calculated densification based on porosity analysis for all the sintered specimens

\begin{tabular}{ccccc}
\hline \multirow{2}{*}{ Specimen } & \multicolumn{4}{c}{ Densification (\%) } \\
\cline { 2 - 5 } & $\begin{array}{c}\text { Low Co } \\
\text { layer }\end{array}$ & $\begin{array}{c}\text { Intermediate } \\
\text { layer }\end{array}$ & $\begin{array}{c}\text { High Co } \\
\text { layer }\end{array}$ & $\begin{array}{c}\text { Average } \\
( \pm 1 \%)\end{array}$ \\
\hline 1H0G & 92 & 95 & 97 & 94 \\
$1 \mathrm{H} 1 \mathrm{G}$ & 97 & 95 & 98 & 96 \\
$1 \mathrm{H} 2 \mathrm{G}$ & 97 & 98 & 98 & 97 \\
$2 \mathrm{H} 0 \mathrm{G}$ & 97 & 96 & 97 & 96 \\
$2 \mathrm{H} 1 \mathrm{G}$ & 97 & 97 & 97 & 97 \\
$2 \mathrm{H} 2 \mathrm{G}$ & 96 & 94 & 97 & 95 \\
\hline
\end{tabular}

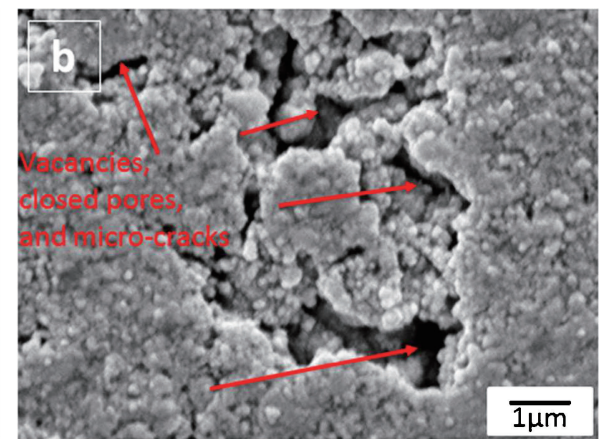

Fig. 5. Microstructural defects appeared in the low Co, hard layer of the G-free specimen 1H0G (a), in comparison to the extra defects appeared in the similar LPS sintered specimen $2 \mathrm{H} 0 \mathrm{G}(\mathrm{b})$.

In fact during LPS of WC-Co composites, where the diffusion and plastic flowing are the dominated densification mechanisms, ${ }^{23), 24)}$ small amount of graphene addition seems to fill up the micro and nano voids resulting in an increase in the relative density of the WC-Co composites. The graphene content larger than $0.2 \%$, seems to be not able to disperse very homogeneously in the liquid phase of WC-Co composites during sintering. The $\mathrm{G}$ sheets would stack together or interact with WC-Co, which in turn may lead to an impediment effect on the mass transportation of diffusion and plastic flow.

It is well known that the density of the LPS sintered samples should be higher than those of solid phase sintered ones. Also it is possible that, some errors occur in measuring the real density of WC-Co sintered specimens due to the unseen phase changes and/or the unavoidable microstructural local defects (delamination, grain boundaries, micro-cracks propagation, etc.). ${ }^{25)}$ For example, Fig. 5 shows the noticed microstructural defects inside the $\mathrm{G}$ free hard surface of the solid phase sintered sample, $1 \mathrm{H} 0 \mathrm{G}$, (a) compared to the similar, but, LPS sintered sample, 2H0G, (b). It is worth to mention that, the extra defects in the case of LPS are generated as a result of the fast liquid Co spreading and the heterogeneous shrinkage, however, it could be minimized if a special attention is paid to the heating and cooling cycle. ${ }^{25), 26)}$ Therefore, porosity analysis becomes of importance to stand on the actual level of consolidation achieved by the activated sintering mechanisms. Based on Image-J analyzer software, the densification results summarized in Table 2, reveals that high consolidation in the range of $95 \%$ was achieved for all composites due to the pressure assisted sintering. In opposite to the previously reported relative density values in Table 1 , here, the direct calculation of the pores portion shows that the liquid state sintered samples - except for the specimen $2 \mathrm{H} 2 \mathrm{G}$ which contains additional shrinkage cracks - got better consolidation than the solid state sintered ones. This may be contributed to the extra 
defects associated with the liquid formation during the current processing conditions, especially, with $G$ addition more than $0.2 \%$. Besides, there is a slight increase in the densification of the high Co layer in all specimens promoted by the spreading of Co binder between the growing WC particles during sintering. Moreover, the results confirmed that, graphene has an essential role in enhancing the densification by preventing WC oxidation and further dissolution in Co binder. ${ }^{27), 28)}$ To avoid any conflict between the results shown in Tables 1 and 2, the LPS conditions increased the densification of the samples, but it also increased the defects in the microstructure which slightly lowered down the relative density of the LPS sintered samples.

Figure 6 presents XRD patterns of $\mathrm{H} 1 \mathrm{G}$ and $\mathrm{H} 2 \mathrm{G}$ specimens after solid (a) and liquid (b) states sintering. The XRD patterns of sintered H0G specimens are included for comparisons. In general, the reflection lines typical of Fcc Co are disappeared, while those typical of Hcp WC tend to shift to higher and lower diffraction angles with the addition of 0.1 and $0.2 \% \mathrm{G}$, respectively, with HIP sintering. The most frequent shifting of XRD peaks for WC-Co composites are usually caused by the high temperature sintering reactions similar to the carbides solubility in Co reported by Chang et al. ${ }^{29)}$ Hence, it is claimed that at the limit of $0.1 \% \mathrm{G}$ there is a full solubility of $\mathrm{G}$ in WC-Co matrix which changes the stoichiometry of the composite and caused the noticed XRD pattern's shift to the higher angles. On the other hand, Increasing $\mathrm{G}$ content to $0.2 \% \mathrm{G}$ is apparently beyond the maximum solubility of $\mathrm{G}$ in $\mathrm{WC}-\mathrm{Co}$, it may cause some internal compressive stresses that impart the shifting of the XRD pattern to the lower angles. ${ }^{30)}$

Moreover, the reflection line typical of the graphene is disappeared when graphene content is of $0.1 \%$ and then reappeared with further increase of graphene content to $0.2 \%$. More noteworthy, no reflection lines typically related to free-carbon nor $\eta$ carbide phase appears in the patterns of the sintered specimens, due to the thermo-mechanical stability of graphene and WC phase. This refers to the fact that the level of $0.1 \%$ graphene corresponds to the maximum solubility of the graphene in the liquid cobalt of WC-Co composites. On the other hand, it is noticed in the diffraction patterns of sintered $\mathrm{H} 1 \mathrm{G}$ and $\mathrm{H} 2 \mathrm{G}$ specimens that the intensity of the Hcp WC reflection lines is

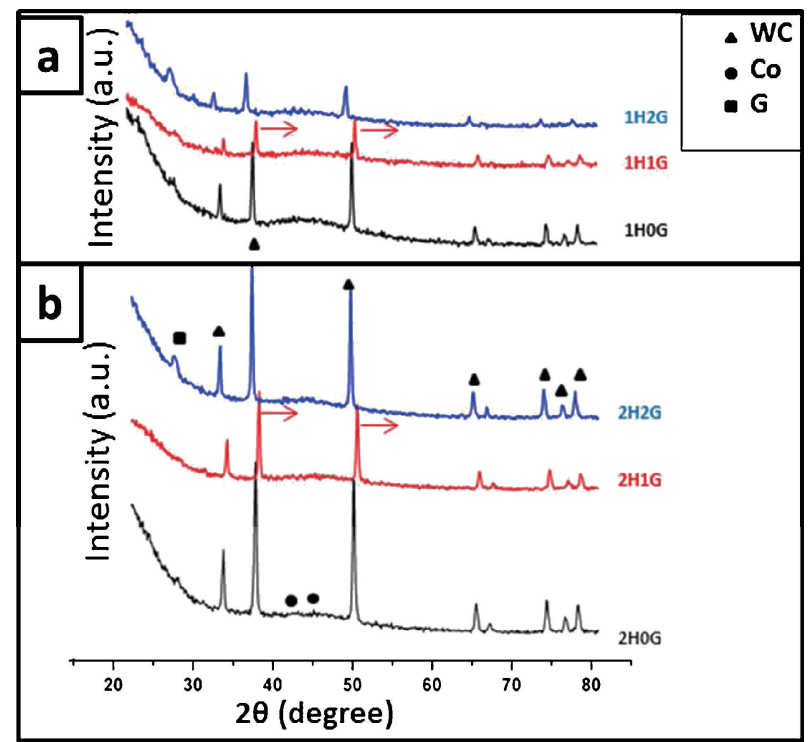

Fig. 6. XRD patterns of $\mathrm{H} 0 \mathrm{G}, \mathrm{H} 1 \mathrm{G}$ and $\mathrm{H} 2 \mathrm{G}$ specimens after solid (a) and liquid (b) states sintering. significantly reduced with graphene addition, particularly with the presence of $0.1 \% \mathrm{G}$, indicating that graphene acts as an inhibitor for the grain growth of WC matrix phase. For instance, the measured mean average crystalline grain size, using Scherer's equation, ${ }^{31)}$ is reduced upon liquid state sintering from $35 \mathrm{~nm}$ for graphene-free WC-Co composite to 25 and $24 \mathrm{~nm}$ in the presence of 0.1 and $0.2 \% \mathrm{G}$, respectively. This indicates that the liquid phase that is saturated with graphene would reduce the solubility of WC, and thereby limit the crazily grain-growth of nanograined WC during the sintering process. ${ }^{1), 6)}$ Carbon rich WC-Co composite in previous studies also shown preferred sintering due to the favored reaction of free carbon with complex carbides according to Eq. (2). ${ }^{11)}$

$$
2 \mathrm{C}+\mathrm{W}_{3} \mathrm{Co}_{3} \mathrm{C} \rightarrow 3 \mathrm{WC}+3 \mathrm{Co} \text { (Liq.) }
$$

Carbon atoms of the active $\mathrm{G}$ sheets tend to diffuse towards the low $\mathrm{C}$ concentration layers in the direction of lower Gibb's free energy. These atoms react positively with Co films at WC grain boundaries and, enhance the reduction of oxide film that prevents the further oxidation and dissolution of WC. Probably, these reactions enhance Co diffusion in the opposite direction of Co homogenization which promote the Co gradient stability in agreement with the previously reported effect of $\mathrm{C}$ in $\mathrm{WC}-\mathrm{Co}$ FGMs. ${ }^{1), 6)}$ It is worth mentioning that the nanostructured WC-Co composite usually offers new opportunities for achieving superior hardness and toughness combinations, and solve the problem of conventional WC-Co composites. ${ }^{4), 14), 23)}$

Figures 7-9 demonstrate SEM images of the cross sectional views for the triple layers structured corresponds to sintered $\mathrm{H} 0 \mathrm{G}, \mathrm{H} 1 \mathrm{G}$ and $\mathrm{H} 2 \mathrm{G}$ specimens, respectively. In these images, it is hardly to observe any microstructural gradient (phases, pores, grain size, etc.) with distance after any of the applied sintered temperatures. However, the images clearly reveal a clear grain growth and closed pore structure, especially, after sintering beyond the limit of LPS, due to the increase of the dissolution and re-precipitation of the WC particles in the diffused liquid Co phase. ${ }^{27), 28)}$

\subsection{Effect of graphene addition on the prede- signed Co gradient after sintering}

Figure 10 represents Co gradient curves based on EDS mapping over cross-sections of sintered H0G, H1G and $\mathrm{H} 2 \mathrm{G}$ specimens after solid (a) and liquid (b) states sintering. As seen in Fig. 10(a), the predesigned Co gradient, of $10 \% \mathrm{Co}$, in the examined specimens is slightly reduced to about $8-9 \%$ of the Co after solid state sintering regardless the amount of graphene

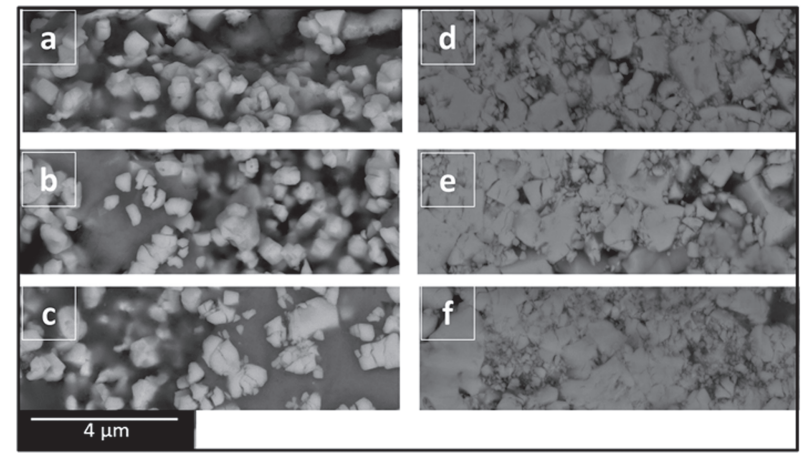

Fig. 7. SEM images for cross section views of as polished $\mathrm{HOG}$ specimens after solid [5\%Co-1H0G (a), 10\% Co-1H0G (b), 15\% Co$1 \mathrm{H} 0 \mathrm{G}(\mathrm{c})]$ and liquid [5\% Co-2H0G (d), 10\% Co-2H0G (e), $15 \% \mathrm{Co}-$ $2 \mathrm{H} 0 \mathrm{G}(\mathrm{f})]$ states sintering. 


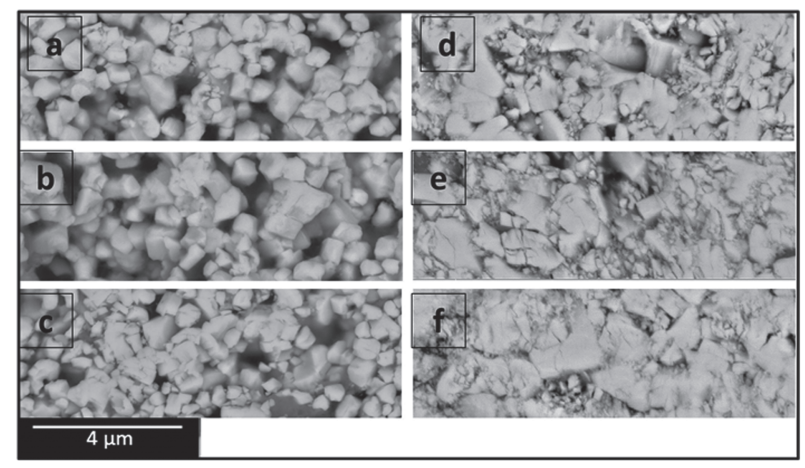

Fig. 8. SEM images for cross section views of as polished $\mathrm{H} 1 \mathrm{G}$ specimens after solid $[5 \% \mathrm{Co}-1 \mathrm{H} 1 \mathrm{G}$ (a), $10 \% \mathrm{Co}-1 \mathrm{H} 1 \mathrm{G}$ (b), $15 \%$ Co$1 \mathrm{H} 1 \mathrm{G} \mathrm{(c)]} \mathrm{and} \mathrm{liquid} \mathrm{[5 \%} \mathrm{Co-2H1G} \mathrm{(d),} \mathrm{10 \%} \mathrm{Co-2H1G} \mathrm{(e),} \mathrm{15 \%} \mathrm{Co-}$ 2H1G (f)] states sintering.

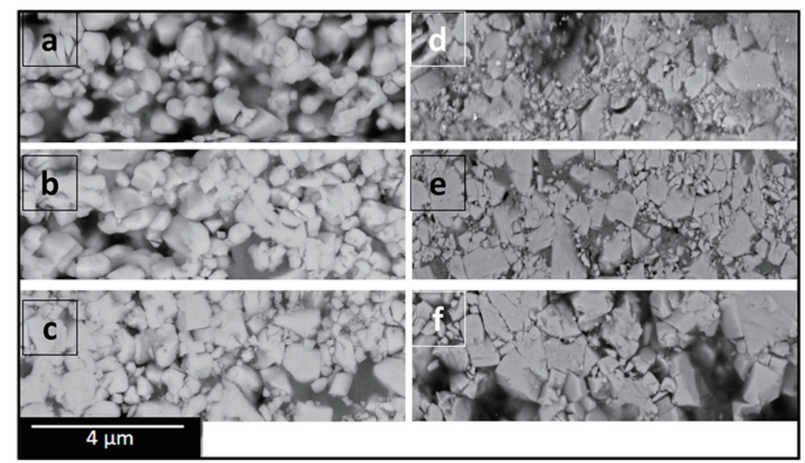

Fig. 9. SEM images for cross section views of as polished $\mathrm{H} 2 \mathrm{G}$ specimens after solid [5\%Co-1H2G (a), 10\% Co-1H2G (b), $15 \%$ Co$1 \mathrm{H} 2 \mathrm{G}(\mathrm{c})]$ and liquid $[5 \% \mathrm{Co}-2 \mathrm{H} 2 \mathrm{G}(\mathrm{d}), 10 \% \mathrm{Co}-2 \mathrm{H} 2 \mathrm{G}(\mathrm{e}), 15 \% \mathrm{Co}-$ $2 \mathrm{H} 2 \mathrm{G}(\mathrm{f})]$ states sintering.

content. The analysis shows an irregular Co distribution over the cross-section of the low temperature sintered specimens due to the liquid Co restriction that accompanies the solid state sintering below the eutectic point. However, the overall trend of the liquid Co was to spread from high to low Co concentration layers driven by Co migration pressure. "Co amplitude" could be counted by the difference of Co content between the two extreme surfaces of WC-Co FGM. Co amplitude is attached to each curve in Figs. 10(a) and 10(b) to compare the Co gradient of the different specimens. In this range of solid state sintering, specimen 1H0G shows the best Co amplitude (9\%) for the current study. On the other hand, the specimen $1 \mathrm{H} 1 \mathrm{G}$ shows the most continuous Co gradient of a comparable Co amplitude. Although, the high temperature sintered specimens showed an interesting and significant $\mathrm{Co}$ gradient for the two specimens with $\mathrm{G}$ agent $(2 \mathrm{H} 1 \mathrm{G}$ and $2 \mathrm{H} 2 \mathrm{G})$, while, the other G-free specimen showed a completely Co gradient loses. Obviously, Co amplitudes of $2 \mathrm{H} 1 \mathrm{G}$ and $2 \mathrm{H} 2 \mathrm{G}$ specimens; (9.5 and, 10\%) are better than those of the specimens $1 \mathrm{H} 1 \mathrm{G}$ and $1 \mathrm{H} 2 \mathrm{G}$; $(7.8$ and $7.9 \%)$ respectively. According to Fan et al. model there are three factors affecting Co migration pressure; Co fraction, WC grain size, and C content. ${ }^{5), 6)}$ In the current situation, $\mathrm{G}$ additive is the only parameter affecting the Co gradient stability, since, the same WC grain size is used in all layers. This means that the presence of graphene surprisingly induces stability to predesigned Co gradient upon liquid state sintering.

The induced stability in the Co gradient after liquid state sintering via graphene addition is being further confirmed by optical
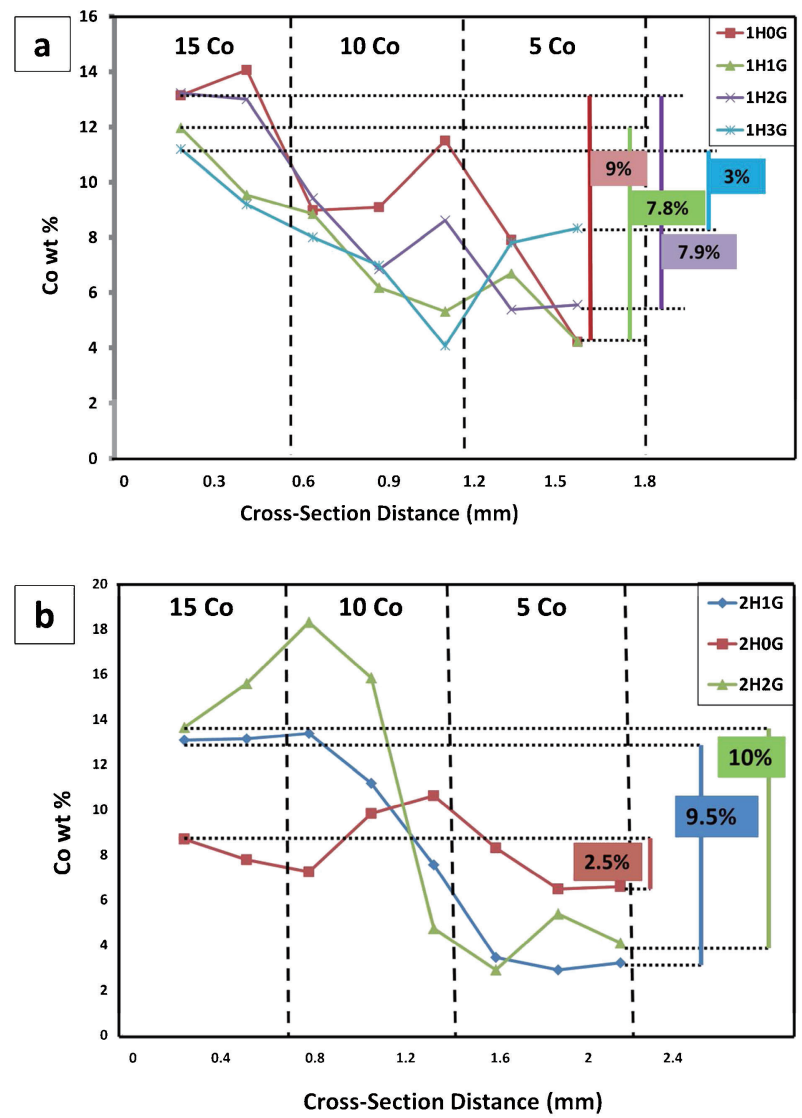

Fig. 10. EDS mapping analysis of the cross-sectional areas of different three-transitional layers of $\mathrm{H} 0 \mathrm{G}, \mathrm{H} 1 \mathrm{G}$ and $\mathrm{H} 2 \mathrm{G}$ specimens after solid (a) and liquid (b) states sintering.

micrographs presented in Figs. 11(a) and 11(b) for 2H0G and $2 \mathrm{H} 2 \mathrm{G}$ specimens, respectively. For $2 \mathrm{H} 0 \mathrm{G}$ specimen, Fig. 10(a), an almost complete homogenization of Co in the overall structure is observed. While, the graphene addition in the intermediate layer as in case of $2 \mathrm{H} 2 \mathrm{G}$ specimen, Fig. 10 (b), created two clearly different microstructural zones separated with an interphase layer. This inter-phase layer seems to stabilize or enhance the liquid phase diffusion of Co from the surface layer with $15 \%$ Co to the bottom layer of 5\% Co in the specimen. Hence, in the case of the LPS, graphene seems to partially or fully dissolve in the cobalt melt and participate in the formation of WC$10 \%$ Co inter-phase layer enhancing the barrier effect of liquid Co diffusion. This phenomenon requires further future detailed analysis.

In brief, the above results demonstrate that the predesigned cobalt gradient in green WC-Co compacts can be stabilized by the graphene addition and manipulating its content during liquid state sintering of the green WC-Co FGM specimens. The maintained Co gradient, inter-phase layer and grain refinement created by graphene addition could be valuable in managing the hardness, wear resistance and fracture toughness of conventional or nanostructured $\mathrm{WC}-\mathrm{Co}$ specimens, being subjected to liquid state sintering.

\subsection{Mechanical properties}

In this section the mechanical properties of WC-Co FGM composites are explored only for the specimens subjected to liquid state sintering, which showed better consolidation com- 
pared to those subjected to solid state sintering. Moreover, due to the recorded low relative density and presence of pores and defects of liquid state sintering, the mechanical property
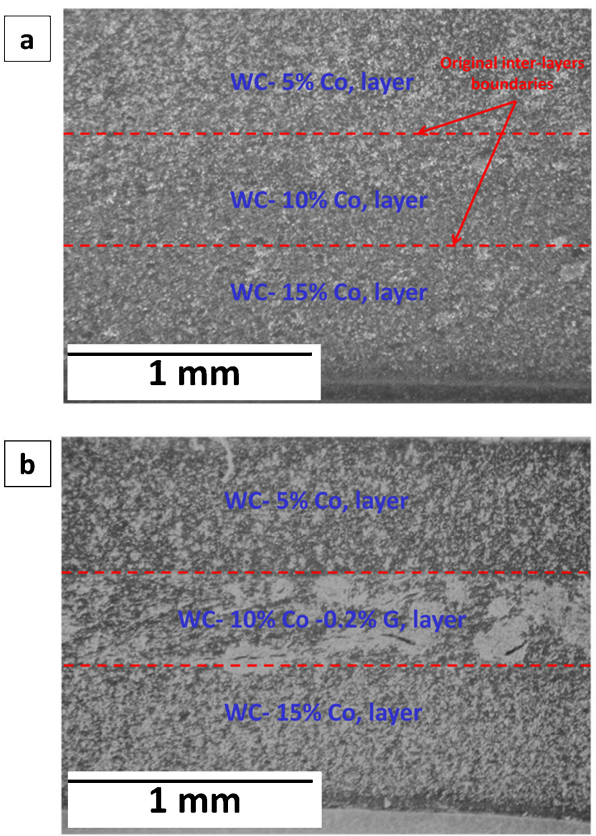

Fig. 11. Cross-sectional overview for H0G (a) and H2G (b) specimens after liquid state sintering.
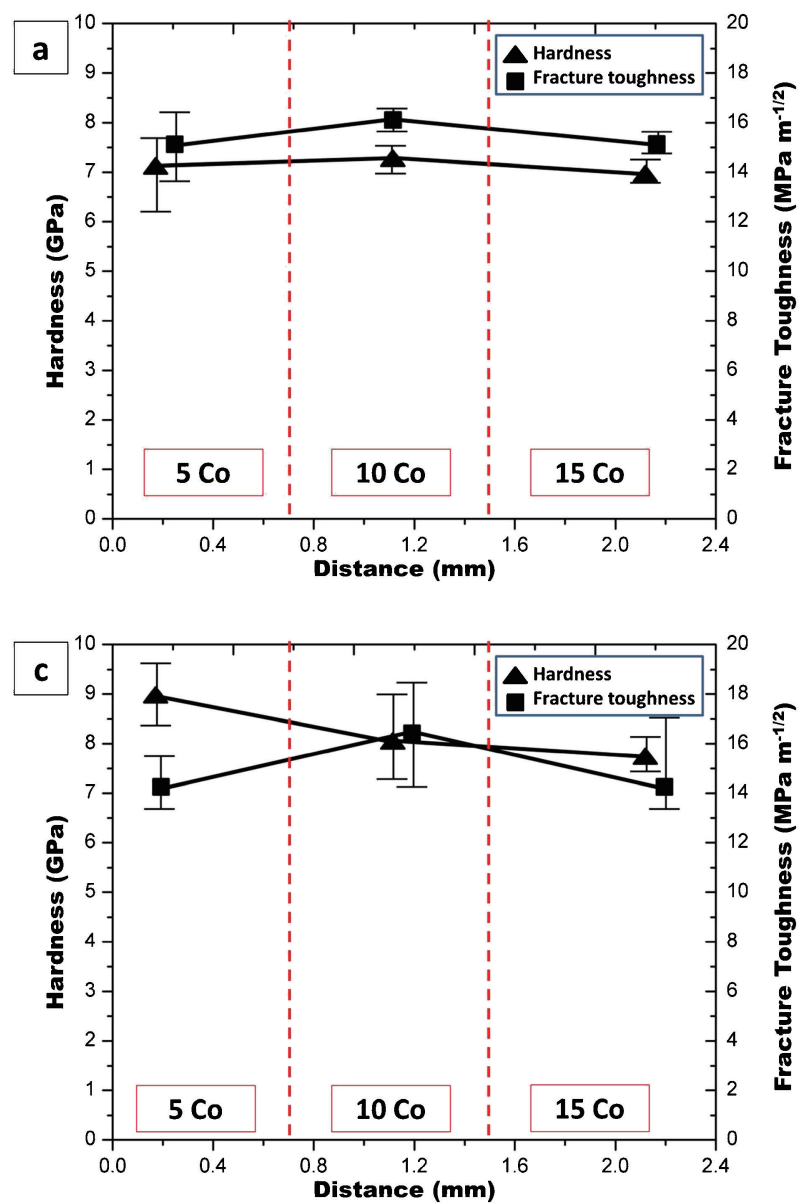

testing of nanostructured WC-Co specimens with and without graphene addition, generally, revealed relatively lower values of hardness compared to those reported for fully densified nanostructured WC-Co composites. ${ }^{1)}$ Therefore, the current section is just exploring the benefits of the functionally graded WCCo-G composites over conventional WC-Co composite with homogeneous structure from the mechanical properties point of view.

Figure 12 shows the cross-sectional change of hardness and fracture toughness for high temperature sintered specimens $2 \mathrm{H} 0 \mathrm{G}$ (a), $2 \mathrm{H} 1 \mathrm{G}$ (b), and 2H2G (c). As seen in Fig. 12(a), the graphenefree $2 \mathrm{H} 0 \mathrm{G}$ specimen shows fastened macro-hardness and fracture toughness with a narrow range of variation along the predesigned three layers. This result is well correlated with the revealed homogeneity in the Co content through the whole structure after the liquid state sintering. Meanwhile, a clear improvement in the hardness without decreasing the fracture toughness of WC-Co composites is generally noticed for the G-modified specimens as shown in Figs. 12(b) and 12(c), though that the composite with $0.1 \%$ graphene, that is $2 \mathrm{H} 1 \mathrm{G}$, presents the best performance. Except for the $G$ modified intermediate layer which almost shows the best mechanical properties among the three consolidated layers, the hardness and fracture toughness at both surface and bottom layers change correspondingly with the pre-designed cobalt gradient. This confirms the reinforcing inducing effect of graphene addition to the nanostructured WC-Co composite. In other words, the nanostructured WC-Co composites coupled with an optimized addition of graphene could offer new opportunities

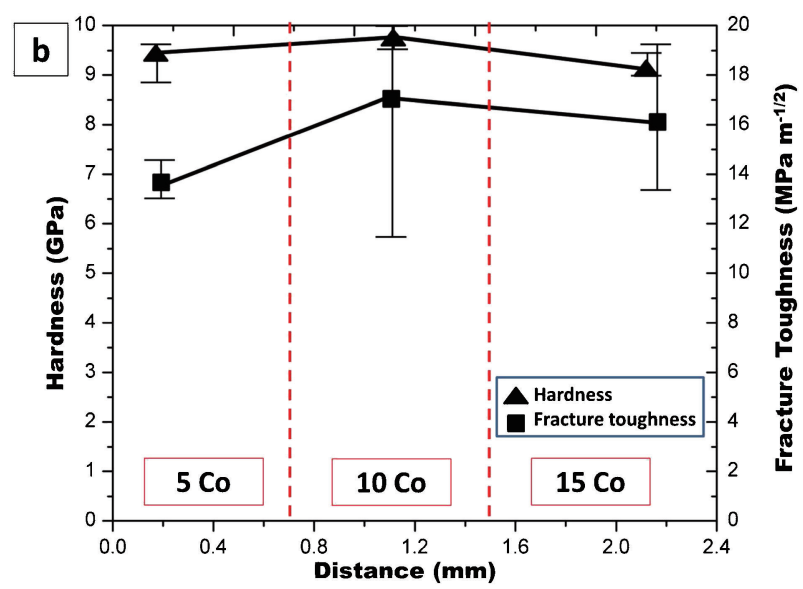

Fig. 12. Hardness and fracture toughness gradient through cross-sectional areas of (a) 2H0G specimen, (b) 2H1G specimen, (c) $2 \mathrm{H} 2 \mathrm{G}$ specimen. 
for achieving better hardness and toughness combinations, and solve the problem of conventional ones.

\section{Conclusion}

The current study could be concluded in some interesting findings; First, mechanical milling shows good refinement and sufficient alloying of WC-Co with and without graphene additives. Also, hot isostatic pressing for the fine WC-Co composite could depress the formation of brittle eta phase in the three transitional-layer structure. Graphene additives to WC-Co multitransitional layer structure results in an interesting uniform microstructure and enhanced consolidation. The graphene addition of $0.1 \mathrm{wt} . \%$ to the middle layer of the three transitional-layer structure, currently, was found to be the optimum to maintain Co gradient and to improve the mechanical properties. Finally, Co gradient can be maintained successfully even using high temperature liquid phase sintering for WC-Co FGM samples of small thickness using graphene. This thin three-transitional layer structure could be a part of higher multi-transitional layer structure suitable for different WC-Co FGM applications.

Acknowledgement The authors would like to acknowledge Dr. Ayman El-said from The Central Metallurgical R\&D Institute in Egypt for his efforts regarding the hot isostatic pressing. Kagawa University in Japan is also acknowledged for supporting the characterization work of this study. The financial support of the Egyptian Ministry of Higher Education through Egypt-Japan University of Science and Technology (E-JUST) is highly appreciated.

\section{References}

1) H. E. Exner and J. Gurland, Powder Metall., 13, 13-31 (1970).

2) P. Fan, Z. Fang and J. Guo, Int. J. Refract. Met. Hard Mater., 36, 2-9 (2013).

3) I. Konyashin, B. Ries, F. Lachmann and A. T. Fry, Int. J. Refract. Met. Hard Mater., 36, 10-21 (2013).

4) X. Wang, K. S. Hwang, M. Koopman, Z. Fang and L. Zhang, Int. J. Refract. Met. Hard Mater., 36, 46-51 (2013).

5) P. Fan, O. Eso, Z. Fang and H. Y. Sohn, Int. J. Refract. Met. Hard Mater., 26, 98-105 (2008).

6) P. Fan, J. Guo and Z. Fang, Int. J. Refract. Met. Hard Mater., 27, 256-260 (2009).
7) Y. Yuan, J. Ding and J. Bai, Int. J. Refract. Met. Hard Mater., 43, 109-114 (2014).

8) M. Tobioka, M. Kodama, T. Asai and T. Yamamoto, Sintered hard metal and the method for producing the same. US4277283A (1981).

9) M. Schwarzkopf, H. E. Exner, H. F. Fischmeister and W. Schintlmeister, Mater. Sci. Eng., A, 105-106, 225-231 (1988).

10) U. Fisher, E. Hartzell and J. Akerman, US patent no; 4743515 (1988).

11) Z. Fang and O. Eso, Scr. Mater, 52, 785-791 (2005).

12) Z. Fang, P. Fan and J. Guo, US patent no; 0101368 (2010).

13) Z. Fang, P. Fan and J. Guo, US patent no; 0116963 (2011).

14) F. Zhang, J. Shen and J. Sun, Mater. Sci. Eng., A, 381, 86-91 (2004).

15) M. Gamil, Sensors Mater., 26, 699-709 (2014).

16) M. El-Asfoury, M. Nasr and K. Nakamura, Jpn. J. Appl. Phys., 55, 699-709 (2016).

17) S. Mohamed, M. Suzuki and A. El-Moneim, Int. J. Electrochem. Sci., 9, 8340-8354 (2014).

18) S. Hassan, M. Suzuki, S. Mori and A. El-Moneim, RSC Advances, 4, 20479-20488 (2014).

19) S. Hassan, M. Suzuki, S. Mori and A. El-Moneim, J. Power Sources, 249, 21-27 (2014).

20) K. Niihara, J. Mater. Sci. Lett., 2, 221-223 (1983).

21) G. Shao, X. Duan, J. Xie, X. Yu and W. Zhang, Rev. Adv. Mater. Sci., 5, 281-286 (2003).

22) G. Gille, B. Szensy, K. Dreyer and G. Leitner, Int. J. Refract. Met. Hard Mater., 20, 3-22 (2002).

23) O. Eso, Z. Fang and A. Griffo, Int. J. Refract. Met. Hard Mater, 23, 233-241 (2005).

24) P. Fan, O. O. Eso, Z. Fang and H. Y. Sohn, Int. J. Refract. Met. Hard Mater, 26, 98-105 (2008).

25) A. Kurlov and A. Gusev, Springer series in material science 184 (2013).

26) P. Chivavibul, J. Therm. Spray Technol., 19, 81-88 (2010).

27) A. Petersson and J. Ågren, Acta Mater., 52, 1847-1858 (2004).

28) A. Petersson, Ph.D thesis, KTH Material Science and Engineering (2004).

29) S.-H. Chang, M.-H. Chang and K.-T. Huang, J. Alloys Compd., 649, 89-95 (2015).

30) B. D. Cullity, Adison-Wesly publishing Company, Inc. (1956).

31) A. El-Moneim, E. Akiyama, H. Habazaki, A. Kawashima, K. Asmai and K. Hashimoto, Corros. Sci., 40, 1513-1532 (1998). 